\title{
Reactivity of Collisionally Activated Dichlorocarbene Dications Studied by Tandem Mass Spectrometry*
}

\author{
Bernard Leyh ${ }^{\dagger}$ and Dimitri Hautot ${ }^{\ddagger}$ \\ Département de Chimic, Université de Liège, B.4000 Sart-Tilman, Liège 1, Belgium
}

The dissociation mechanisms of dichlorocarbene dications following collisional activation have been investigated via tandem mass spectrometric techniques and semi-empirical calculations. Three channels appear to be significant:

$$
\begin{aligned}
& \mathrm{CCl}_{2}^{2+} \rightarrow \mathrm{CCl}^{+}\left(X^{1} \Sigma^{+}\right)+\mathrm{Cl}^{\cdot}\left({ }^{3} P\right) \quad \text { (channel 1) } \\
& \mathrm{CCl}_{2}^{2 *} \rightarrow \mathrm{CCl}^{*}\left(X^{\prime} \Sigma^{*}\right)+\mathrm{Cl}^{*}\left({ }^{1} D\right) \quad \text { (channel 2) } \\
& \mathrm{CCl}_{2}^{2} \rightarrow \mathrm{Cl}_{2}^{*}\left(X^{2} \Pi_{x^{\prime}}\right)+\mathrm{C}^{\prime}\left({ }^{2} P\right) \text { (channel 3) }
\end{aligned}
$$

The second channel becomes dominant at high internal energy. Production of ground state fragments (channel 1) involves a transition driven by spin-orbit coupling from the $\mathrm{CCl}_{2}^{2}+\tilde{X}^{1} \underline{-}_{k}$ state to the $\mathrm{CCl}_{2}^{2} \bar{a}^{3} \underline{\Sigma}_{4}$ state en route to the fragments. The dissociation barrier for the production of ground state fragments from the ground electronic state of $\mathrm{CCl}_{2}^{2}$ via the spin-orbit-induced transition is equal to $420 \mathrm{~kJ} \mathrm{~mol}{ }^{1}$. The dissociation pathway that corresponds to channel 3 includes a first isomerization step from the linear $\mathrm{Cl}-\mathrm{C}-\mathrm{Cl}^{2}$ + structure to a bent $\mathrm{Cl}-\mathrm{Cl}-\mathrm{C}^{2+}$ connectivity. The calculated isomerization barrier amounts to $550 \mathrm{~kJ} \mathrm{~mol}^{-1}$. The calculated reverse activation barriers are compatible with the measured kinetic energy released on the fragments. (J Am Soc Mass Spectrom 1995, 6, 1019-1029)

$\mathrm{T}$ andem mass spectrometry is a powerful technique for analytical purposes as well as for basic studies on the structure and reactivity of ions and neutrals [1-4]. From the latter point of view, the application of this methodology to the study of doubly charged cations provides us with a wealth of data that concern the dissociation channels of these species and the energetics associated with their reactions [5-12]. Doubly charged ions have become popular because they display quite interesting features [13]: their dissociation may proceed by tunneling through a barrier induced by nonadiabatic effects; they release an important amount of kinetic energy upon dissociation; they may be stable or metastable although their neutral or singly charged counterpart is unstable. A recent re-

Address reprint requests lo Bernard levh, Departement do Chimie Générale et de Chimie Physique, Institut de Chimic, Baitinnent Bh, Universite de Liege, B.4000 Sart-Tilman, liege I, Belgium.

' Dedicated to P'rofessor F. W. McLafferty in recognition of his semi. nal contributions to the field of mass spectrometry"

Chercheur qualifie du Funds National de la Recherche Scientificlue (Belgium).

Present affiliation: Department of Chemistry, Unicersity of Missouri-Rolla, Rolla MO 65+01-0249. view article on these ions [11] mentions the following essential questions that need to be solved:

"1. Why are multiply charged molecular ions stable (or metastable)?

2. What is the equilibrium geometry for which they are stable?

3. What are the electronic configurations for which they are stable?

4. What are their dissociation pathways, and what potential barriers do they cross (or tunnel through) before dissociation?"

The present paper addresses these questions in the case of the dichlorocarbene dication by using both experimental and theoretical methods. Carbenes are very reactive species that play an important role in organic synthesis [14]. Most of the available data concern neutral dichlorocarbene, and data on the positive and negative ions are in fact relatively scarce. Infrared spectra of $\mathrm{CCl}_{2}^{+}$trapped in a solid argon matrix were reported by Andrews and Keelan [15]. Nguyen et al. [16] performed ab initio calculations on the electronic states of both neutral and singly ionized dichlorocar- 
bene. Rademann et al. [17] measured the adiabatic ionization energy of $\mathrm{CCl}_{2}$, which is equal to $9.1 \mathrm{eV}$. The heat of formation of $\mathrm{CCl}_{2}$ derived from this value is in agreement with recent data of Paulino and Squires [18]. Leyh and Wankenne [19] identified the first quartet state of $\mathrm{CCl}_{2}^{+}$in charge-reversal experiments. Relevant data also can be found in works that deal with the dissociation pathways of $\mathrm{CCl}_{+}^{+}$and other ionized halocarbons [20-27]. These studies led, among other findings, to the characterization of two isomeric structures for $\mathrm{CCl}_{4}^{+}$. The first data on the $\mathrm{CCl}_{2}^{2+}$ dication were obtained via charge-stripping experiments by Proctor et al. [28]. Such experiments under high resolution conditions led Langford et al. [29] to the determination of the minimum energy requirement $Q_{\min }$ for charge stripping of $\mathrm{CCl}^{+}$and $\mathrm{CCl}_{2}^{+}$, from which the enthalpy of formation of the dications can be deduced. Leiter et al. [24] measured the appearance energy of $\mathrm{CCl}_{\mathrm{n}}^{2+}$ ions produced upon electroionization of $\mathrm{CCl}_{4}$. A few studies $[23,30,31]$ also are concerned with the dissociation dynamics of doubly charged tetrachloromethane: they basically show that two isomers are involved in the dissociations of this dication.

Dissociation of a dication into singly charged cations is characterized by a repulsive long-range potential. If the dication is stable or metastable, its potential energy surface must display a minimum at the equilibrium geometry. As a consequence, a barrier necessarily arises along the dissociation path. As will be discussed later in this paper, the situation is made more complicated in the $\mathrm{CCl}_{2}^{2+}$ case because the ground state of the molecular dication $\bar{X}^{1} \Sigma_{p}^{+}$, which is a singlet, does not correlate with the ground state fragments, $\mathrm{CCl}^{+}\left(X^{1} \Sigma^{+}\right)+\mathrm{Cl}^{+}\left({ }^{3} P\right)$, whereas the first excited state $\tilde{a}^{3} \Sigma_{u}^{-}$does. It may therefore be anticipated that a spin-orbit coupling must govern the dissociation dynamics along this coordinate.

The methodology followed in this article is the following. In the experimental part of the work (Experimental Results), we first of all remeasure the appearance energy of $\mathrm{CCl}_{2}^{2+}$ under electron impact conditions to confirm the thermochemistry of this ion. We then investigate its reactivity along the two lowest energy dissociation channels that lead to singly charged fragments: $\mathrm{CCl}^{+}+\mathrm{Cl}^{+}$and $\mathrm{Cl}_{2}^{+}+\mathrm{C}^{+}$. This is performed by measurement of the fragment ion spectra under collisional activation conditions (CAD) with various target gases and measurement of the kinetic energy released on the dissociation fragments. Special care has to be taken here because the collisional activation process being investigated competes with dissociative single-electron capture (SEC):

$$
\begin{aligned}
\mathrm{CCl}_{2}^{2+}+G & \rightarrow \mathrm{CCl}_{2}^{2+,} \\
+\mathrm{G} ; \mathrm{CCl}_{2}^{2+} \cdot \cdot & \rightarrow \text { fragments (CAD) } \\
\mathrm{CCl}_{2}^{2+}+\mathrm{G} & \rightarrow \mathrm{CCl}_{2}^{+} \\
+\mathrm{G}^{+} ; \mathrm{CCl}_{2}^{+} & \rightarrow \text { fragments (SEC) }
\end{aligned}
$$

The single-electron-capture process will be studied in a forthcoming paper. Semiempirical cross sections of the relevant potential energy surfaces, which help to interpret the experimental branching ratios and kinetic energy releases, are presented in the Semiempirical Calculations and Discussion sections.

\section{Experimental}

The experimental data were recorded via an AEI-MS9 forward geometry mass spectrometer equipped with a polarizable and differentially pumped collision cell in the first and in the second field-free regions.

Appearance energies were measured by the vanishing current method by using a pulse-counting detection technique $[32,33]$. The electron energy scale was calibrated by using rare gases under identical experimental conditions.

Fragment ion spectra for decompositions that take place in the first field-free region are obtained by linked scanning of the electrostatic analyzer and the magnet while the E/B ratio is maintained constant [34]. The magnetic field is monitored via a Hall probe. For decompositions of doubly charged ions into singly charged ions, the source accelerating voltage is set at half the value needed to record the corresponding spectrum for singly charged ions.

Ion kinetic energy spectra generated by decompositions that occur in the collision cell located in the first field-free region are recorded by the accelerating voltage scan technique [35]. The ion kinetic energy is equal to $z e V_{\text {acc, }}$, where $z$ is the number of charges of the precursor ion and $V_{\text {acc }}$ is the accelerating voltage.

The experimental conditions were as follows: trap current, $30 \mu \mathrm{A}$; electron energy, $70 \mathrm{eV}$, except for the appearance energy measurements; accelerating voltage for linked scanning at constant $B / E, 4 \mathrm{kV}$; mass resolution, $1000 . \mathrm{CCl}_{2}^{2+}$ results from dissociative electroionization of $\mathrm{CCl}_{4} . \mathrm{CCl}_{4}$ (research grade, $99.8 \%$ purity) was used without further purification except freezepump-thaw cycles to remove dissolved gases. The target gases had the following purities: rare gases, $>99.99 \%$; nitrogen, $99.8 \%$; benzene, $99.7 \%$. The target gas pressure was in most experiments such that the primary beam transmittance was equal to or higher than $90 \%$ : this ensures single-collision conditions [36, 37]. In the ion kinetic energy spectrum for the $\mathrm{CCl}_{2}^{2}{ }^{2} \rightarrow$ $\mathrm{Cl}_{2}^{+}+\mathrm{C}^{+}$dissociation, the transmittance was equal to $70 \%$. Under these conditions, each affected projectile undergoes on average 1.2 collision [36]. Data also were obtained with He at $30 \%$ transmittance (two collisions per affected species [36]) to investigate the effect of increasing the deposited internal energy.

\section{Experimental Results}

\section{Appearance Energy of $\mathrm{CCl}_{2}^{2+}$}

By the vanishing current method, we determined an appearance energy of $32.1 \pm 0.5 \mathrm{eV}$ for $\mathrm{CCl}_{2}^{2+}$ from $\mathrm{CCl}_{4}$, which is in reasonable agreement with the 31.8 
$\pm 0.3 \mathrm{eV}$ value obtained by Leiter et al. [24]. From this appearance energy and known thermochemical data $[38,39]$, we deduce that the heat of formation of $\mathrm{CCl}_{2}^{2+}$ is equal to $2741 \mathrm{~kJ} \mathrm{~mol}^{-1}$. This value has to be compared with that deduced from the charge-stripping experiments of Langford et al. [29]. If we adopt a $Q_{\min }$ value of $16.4 \mathrm{eV}$ for the energy balance of the $\mathrm{CCl}_{2}^{+} \rightarrow$ $\mathrm{CCl}_{2}^{2+}$ charge-stripping process, we get $2690 \mathrm{~kJ} \mathrm{~mol}^{-1}$ for the heat of formation of the dichlorocarbene dication. Figure 1 displays the energetics of the different dissociation channels of $\mathrm{CCl}_{2}^{2}+$ obtained by using the available thermochemical data [38, 39]. This figure shows clearly that the $\mathrm{CCl}^{+}+\mathrm{Cl}^{+}$and the $\mathrm{Cl}_{2}^{+}+\mathrm{C}^{+}$ channels are the most favorable and that they are energy-decoupled from the more energy-demanding channels by about $4 \mathrm{eV}$.

\section{Fragment Ion Spectra of $\mathrm{CCl}_{2}^{2+}$}

Figure 2 shows one example of the collision-activated dissociation (CAD) spectra of $\mathrm{CCl}_{2}^{2}$, ions that decay into singly charged fragments, obtained by linked scanning of the electrostatic analyzer and the magnet at constant $\mathrm{B} / \mathrm{E}$. Table 1 gives the branching ratios deduced from these spectra. These data were obtained by integration of the peak areas rather than by measurement of the peak heights.

As expected on a thermochemical basis, the $\mathrm{CCl}^{+}+$ $\mathrm{Cl}^{+}$channel is more favored than the $\mathrm{Cl}_{2}^{+}+\mathrm{C}^{+}$channel. A general tendency is that the branching ratio for $\mathrm{Cl}_{2}^{+}$formation decreases when the target gas ionization energy decreases. To interpret these data, we must remember, however, that collisional activation of the dication competes with dissociative single-electron capture. The CAD yield is expected to decrease when

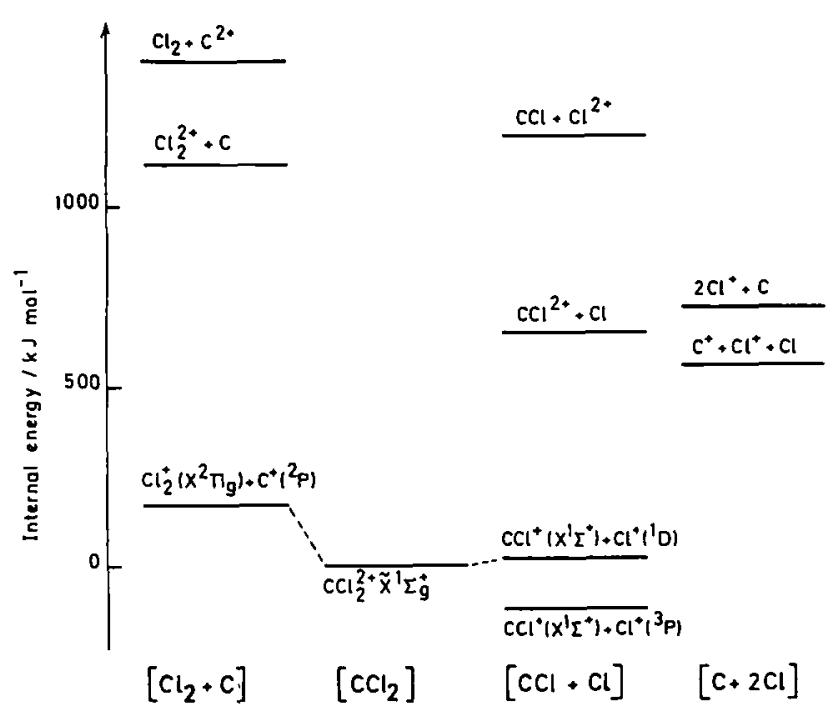

Figure 1. Thermochemical data relevant to the dissociation processes of $\mathrm{CCl}_{2}^{2+}$. Unless otherwise stated, the energies mentioned correspond to the ground electronic state species.

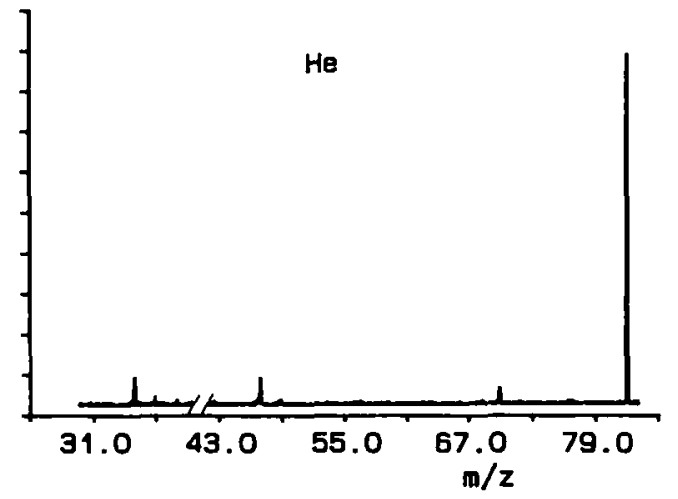

Figure 2. Fragment ion spectrum obtained upon collision between 8-keV $\mathrm{CCl}_{2}^{2}$, ions and $\mathrm{He}$ atoms. The target gas pressure corresponds to a precursor beam transmittance of $90 \%$. This spectrum was obtained by linked scanning of the electrostatic analyzer and the magnet at a constant $B / E$ ratio.

the target ionization energy is decreased [40]. Based on the thermochemical balance of eq 2, the internal energy deposited in the projectile upon SEC, however, should display the opposite trend, at least for exothermic SEC. Furthermore, the branching ratio between CAD and SEC varies from one target gas to the other. The observed ion intensities result therefore from a complicated balance between these conflicting effects. It is not possible to differentiate between the contributions of $\mathrm{CAD}$ and dissociative $\mathrm{SEC}$ in a fragment ion spectrum. Differentiation is possible, however, in an ion kinetic energy spectrum because both processes are characterized by very different amounts of kinetic energy released on the fragments, as will be discussed in the next subsection.

Ion Kinetic Energy Spectra for the $\mathrm{CCl}_{2}^{2+} \stackrel{\mathrm{CAD}}{\longrightarrow} \mathrm{CCl}^{+}+\mathrm{Cl}^{+}$Reaction

Figure 3 shows the ion kinetic energy spectra obtained with various target gases for the $\mathrm{CCl}_{2}^{\frac{2}{+}} \rightarrow \mathrm{C}^{35} \mathrm{Cl}^{+}+\mathrm{Cl}^{+}$ dissociation, obtained via the accelerating voltage scan technique [35]. The complicated pattern observed results from two facts:

1. This scanning technique gives a parent ion spectrum of the $\mathrm{C}^{3.5} \mathrm{Cl}^{+}$ion. As a result, dissociation of both $\mathrm{C}^{35} \mathrm{Cl}_{2}^{2+}$ and $\mathrm{C}^{35} \mathrm{Cl}^{37} \mathrm{Cl}^{2+}$ contributes to the ion signal.

2. The electrostatic repulsion between the positively charged fragments that result from CAD gives rise to a large kinetic energy release and thus to a dish-topped peak, whereas dissociative SEC results in a much lower average kinetic energy release, characteristic of the corresponding singly charged cation, and thus to a Gaussian-like peak. 
Table 1. Branching ratios for the different fragment ions that result from the collision between $\mathrm{CCl}_{2}^{2+}$ and various target gases $^{n}$

\begin{tabular}{|c|c|c|c|}
\hline Target gas & Ionization energy (eV) & $\begin{array}{l}\left./^{35} \mathrm{Cl}_{2}\right)^{\prime} \\
\left(\mathrm{C}^{35} \mathrm{Cl}^{-}\right)\end{array}$ & $\begin{array}{l}/\left(^{35} \mathrm{Cl}^{-1}\right) / \\
/\left(\mathrm{C}^{35} \mathrm{Cl}^{\cdot}\right)\end{array}$ \\
\hline $\mathrm{He}$ & 24.59 & 0.50 & 0.69 \\
\hline $\mathrm{Ne}$ & 21.56 & 0.27 & 0.36 \\
\hline Ar & 15.76 & 0.06 & 0.46 \\
\hline $\mathrm{Kr}$ & 14.00 & 0.04 & 0.11 \\
\hline $\mathrm{Xe}$ & 12.13 & 0.10 & 0.11 \\
\hline $\mathrm{N}_{2}$ & 15.58 & 0.04 & 0.35 \\
\hline $\mathrm{CCl}_{4}$ & 11.47 & 0.01 & 0.14 \\
\hline $\mathrm{C}_{6} \mathrm{H}_{6}$ & 9.25 & 0.04 & 0.08 \\
\hline
\end{tabular}

${ }^{a}$ These data result from the measurement of peak areas in the daughter ion spectra obtained by linked scanning at constant $B / E$.

We expect therefore the presence of six maxima, but only four of them are observable due to their partial overlap. It must be mentioned, however, that the first and the last peaks do not overlap with the others. Each of these two peaks is one of the maxima of the dish-topped signal that arises from the dissociation of $\mathrm{C}^{35} \mathrm{Cl}_{2}^{2+}$ and of $\mathrm{C}^{35} \mathrm{Cl}^{37} \mathrm{Cl}^{2+}$, respectively. From the positions of these maxima, it is possible to estimate the value of $\varepsilon_{\min }$, the minimum amount of kinetic energy released upon $C A D$. In the particular case studied here, the following system of equations has to be solved:

$$
\begin{aligned}
& \varepsilon_{\min }=\frac{\left(E_{\mathrm{k}, 0}-E_{\mathrm{k}}\right)^{2}}{4 E_{\mathrm{k}, 0)}} \frac{m_{\mathrm{C}^{15} \mathrm{Cl}}}{m m^{\mathrm{in} \mathrm{Cl}}}
\end{aligned}
$$

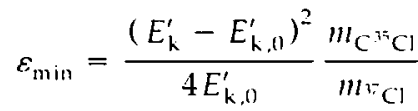

$$
\begin{aligned}
& E_{\mathrm{k}, 0}^{\prime}=E_{\mathrm{k}, 0} \frac{m_{\mathrm{C}^{35} \mathrm{Cl}^{17} \mathrm{Cl}}}{m_{\mathrm{C}^{35} \mathrm{Cl}}}
\end{aligned}
$$

where $m_{X}$ is the mass of fragment $X, E_{\mathrm{k}}\left(E_{\mathrm{k}}^{\prime}\right)$ is the kinetic energy corresponding to the first (last) peak, and $E_{\mathrm{k}, 0}\left(E_{\mathrm{k}, 01}^{\prime}\right)$ is the kinetic energy corresponding to $\mathrm{C}^{35} \mathrm{Cl}^{+}$ions from $\mathrm{C}^{35} \mathrm{Cl}_{2}^{2+}\left(\mathrm{C}^{35} \mathrm{Cl}^{37} \mathrm{Cl}^{2+}\right)$ without energy release in the direction of detection ( $x$ direction). Equations (3) and (4) are standard [41]. They relate the ion kinetic energy in the laboratory frame $\left(E_{k}\right.$ and $\left.E_{k}^{\prime}\right)$ to the energy released on the fragments in the center of mass frame (molecular frame), $\varepsilon_{\min }$. These equations neglect translational energy losses associated with CAD. These losses are, however, small $(0-10 \mathrm{eV})$ [40] compared to the signal broadening due to kinetic energy release $(-800 \mathrm{eV}$ in the present case).

The numerical analysis of these composite spectra has been performed by the two methods that are described below. Both methods yield similar results, within experimental errors. In the first procedure, each CAD signal has been adjusted to three Gaussian functions-one for each peak and a wider one for the central part. Each dissociative SEC contribution has been described by one Gaussian function. The entire
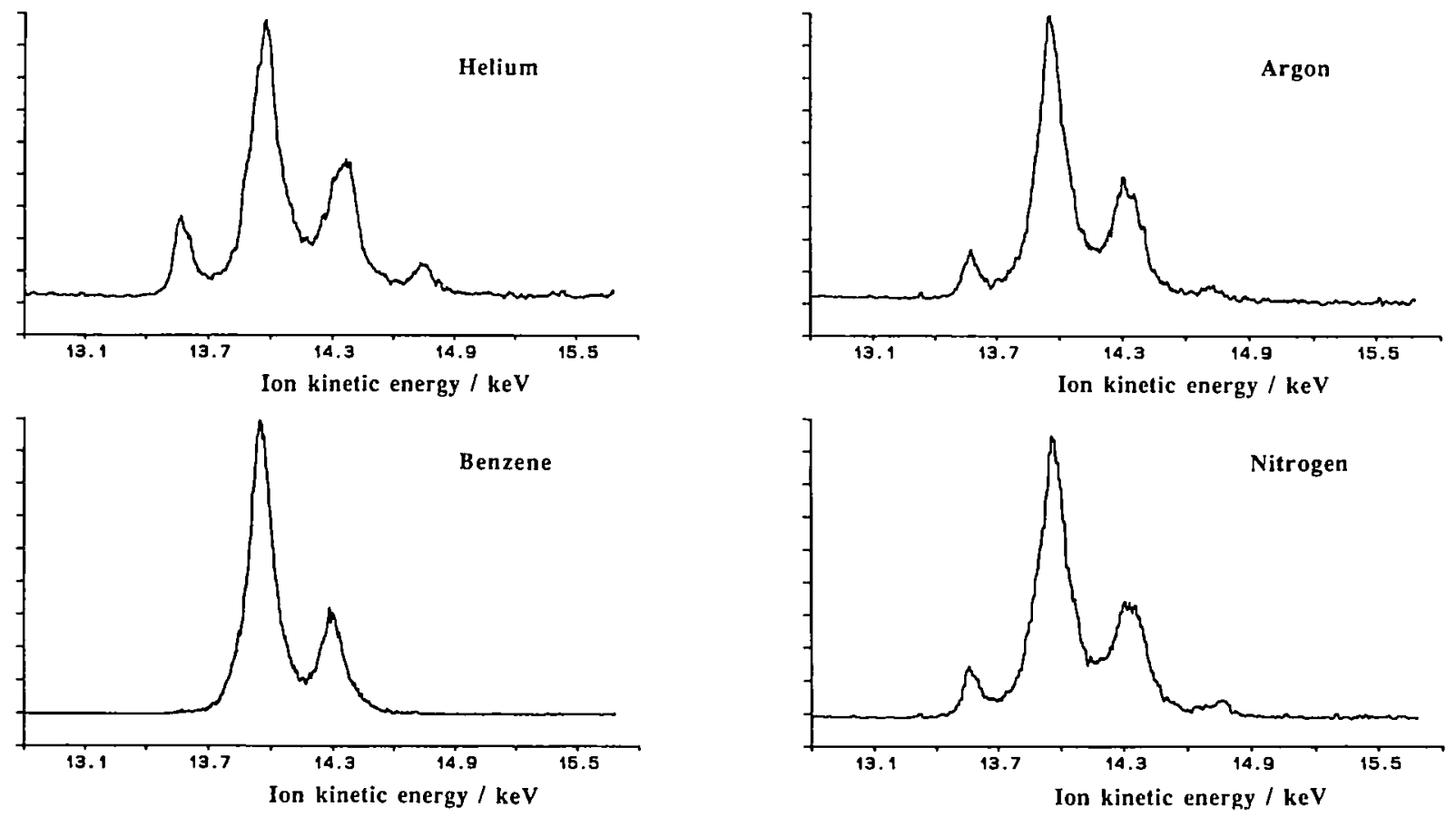

Figure 3. $\mathrm{CCl}^{+}$ion kinetic energy spectrum obtained by the accelerating voltage scan technique. $\mathrm{CCl}^{+}$ions result from collision between $\mathrm{CCl}_{2}^{2}+$ ions and various target gases. Primary beam transmittance: $90 \%$. The target gases are mentioned on the figure. 
spectrum was thus fitted to a weighted sum of eight Gaussian functions with adjustable heights, widths, and centers. The $E_{k}$ and $E_{k}^{\prime}$ values obtained by this method can be introduced in eqs $3-5$ to calculate $\varepsilon_{\text {min }}$, and the knowledge of the different Gaussian contributions allows us to calculate the ratio of the integrated CAD and dissociative SEC signals. A second procedure consisted of adjusting the part of the spectrum that corresponds to $\mathrm{C}^{35} \mathrm{Cl}_{2}^{2+}+G \rightarrow \mathrm{C}^{35} \mathrm{Cl}^{+}+{ }^{35} \mathrm{Cl}+\mathrm{G}^{+}$ (dissociative SEC) to the sum of a constant (the CAD background) plus two Gaussian functions (for the SEC contribution). The signal that corresponds to the other dissociative SEC process, $\mathrm{C}^{37} \mathrm{Cl}^{35} \mathrm{Cl}^{2+}+G \rightarrow \mathrm{C}^{35} \mathrm{Cl}^{+}$ $+{ }^{37} \mathrm{Cl}+\mathrm{C}^{+}$, was then calculated based on the known isotopic abundance ratio and kinematic relations, and by assuming that both SEC processes are characterized by the same kinetic energy release distribution. The sum of both SEC signals was then subtracted from the experimental spectrum, which left us with a "pure" CAD spectrum. This procedure, like the first one, allowed us to determine (i) the minimum kinetic energy released on the $C A D$ fragments and (ii) the branching ratio between $\mathrm{CAD}$ and dissociative SEC. These data are summarized in Table 2 . The errors that are given take into account both the experimental reproducibility and the discrepancies between the two data handling procedures.

These data show first of all that the importance of CAD compared to dissociative SEC decreases when the target gas ionization energy decreases; it becomes barely detectable for $\mathrm{C}_{6} \mathrm{H}_{6}$ and $\mathrm{CCl}_{4}$. From this point of view, argon and nitrogen, which have about the same ionization energy, behave very similarly. This similar behavior also manifests itself in the kinetic energy release data. This tends to support the dominant role played by the ionization energy in high energy collisional processes [40].

Analysis of Table 2 reveals that the amount of kinetic energy released on the fragments decreases with decreasing target ionization energy. This amount of kinetic energy release can be described as the sum of two terms: a constant term associated with the reverse activation barrier and a nonfixed term associated with the internal energy in excess of the dissocia- tion barrier [3]. For a reaction that obeys the hypotheses of statistical theories, this latter term can usually be related to the excess internal energy by Klot's equation [42-46]:

$$
\begin{aligned}
E^{\ddagger}= & \bar{\varepsilon}^{\ddagger}+\frac{r-1}{2} \bar{\varepsilon}^{\ddagger}+\sum_{i=1}^{s_{1}} \frac{h \nu_{i}}{\exp \left(h \nu_{i} / \bar{\varepsilon}^{\ddagger}\right)-1} \\
& +\sum_{i=1}^{s_{2}} \frac{h \nu_{i}}{\exp \left(h \nu_{i} / \bar{\varepsilon}^{\ddagger}\right)-1}
\end{aligned}
$$

where $E^{\ddagger}$ is the internal energy in excess of the barrier, $\bar{\varepsilon}^{\ddagger}$ is the average kinetic energy that results from the redistribution of the excess internal energy $E^{\ddagger}, r$ is the total number of rotational degrees of freedom of both fragments, $s_{1}$ and $s_{2}$ are, respectively, the number of vibrational degrees of freedom of each fragment, and $\nu_{i}$ are the vibrational frequencies in the harmonic approximation. By analyzing the first part of the $\mathrm{C}^{35} \mathrm{Cl}_{2}^{2+} \rightarrow \mathrm{C}^{35} \mathrm{Cl}^{+}+{ }^{35} \mathrm{Cl}^{+}$ion kinetic energy spectrum (i.e., the first peak in Figure 3 ) by the Holmes-Osborne procedure for dish-topped signals [47], estimates of the average kinetic energy release $\bar{\varepsilon}^{\ddagger}$ can be obtained: these are mentioned in the third column of Table 2. Application of eq 6 with a $\mathrm{C}-\mathrm{Cl}^{+}$vibrational frequency of $1120 \mathrm{~cm}^{-1}$ obtained at the semiempirical modified neglect of differential overlap MNDO level [48] enabled estimation of the average internal energy $E^{\ddagger}$ in excess of the dissociation barrier (fourth column of Table 2). Despite the experimental errors and the uncertainties linked with both the Holmes-Osborne procedure and the use of eq 6 , these results show the tendency of the average internal energy deposited in the doubly charged dichlorocarbene upon collision to decrease with decreasing target ionization energy.

The fraction of the reverse activation energy that will appear as kinetic energy of the fragments is governed by the so-called exit channel interactions, that is, the interactions between the reaction coordinate and the fragment internal degrees of freedom-here essentially the $\mathrm{C}-\mathrm{Cl}$ vibration. At large interfragment distances, the potential energy along the reaction coordinate is dominated by the ion-ion coulombic repulsion. The semiempirical calculations that will be discussed

Table 2. Minimum kinetic energy released on the $\mathrm{CCl}^{+}+\mathrm{Cl}^{+} \mathrm{CAD}$ fragments, average kinetic energy release that results from the redistribution of the excess (i.t., nonfixed) internal energy $E^{\ddagger}$, excess internal energy $E^{\ddagger}$ estimated from Klot's equation, and the ratio between CAD and dissociative SEC cross sections for the $\mathrm{CCl}^{+}$production

\begin{tabular}{llccc}
\hline $\begin{array}{c}\text { Target } \\
\text { gas }\end{array}$ & \multicolumn{1}{c}{$\varepsilon_{\text {min }}(\mathrm{eV})$} & $\bar{\varepsilon}^{\ddagger}=\bar{\varepsilon}-\varepsilon_{\min }(\mathrm{eV})$ & $E^{\ddagger}(\mathrm{eV})$ & $\begin{array}{c}\text { CAD/SEC } \\
\text { ratio }\end{array}$ \\
\hline $\mathrm{He}$ & $3.9 \pm 0.05$ & $1.2 \pm 0.2$ & $2.9 \pm 0.5$ & $0.9 \pm 0.2$ \\
$\mathrm{Ne}$ & $3.8 \pm 0.1$ & $1.2 \pm 0.2$ & $2.9 \pm 0.5$ & $0.6 \pm 0.1$ \\
$\mathrm{Ar}$ & $3.8 \pm 0.1$ & $1.0 \pm 0.2$ & $2.4 \pm 0.5$ & $0.47 \pm 0.05$ \\
$\mathrm{Kr}$ & $3.6 \pm 0.1$ & $1.0 \pm 0.2$ & $2.4 \pm 0.5$ & $0.27 \pm 0.03$ \\
$\mathrm{Xe}$ & $3.5 \pm 0.1$ & $0.7 \pm 0.2$ & $1.7 \pm 0.5$ & $0.15 \pm 0.02$ \\
$\mathrm{~N}_{2}$ & $3.8 \pm 0.1$ & $1.0 \pm 0.2$ & $2.4 \pm 0.5$ & $0.45 \pm 0.05$ \\
$\mathrm{CCl}_{4}$ & Low intensity CAD & & & $0.06 \pm 0.01$ \\
$\mathrm{C}_{6} \mathrm{H}_{6}$ & Low intensity CAD & & & $0.04 \pm 0.003$ \\
\hline
\end{tabular}


in the next section show that this term dominates indeed down to interfragment separations of about 6 $\AA$, where the orbitals of $\mathrm{CCl}^{+}$and $\mathrm{Cl}^{+}$start to overlap. At smaller distances, however, the interaction between the reaction coordinate and the $\mathrm{C}-\mathrm{Cl}$ vibration remains small, so that the lowest kinetic energy release observed (with xenon as the target gas) gives most probably a good estimate of the reverse activation barrier.

\section{Ion Kinetic Energy Spectra for the $\mathrm{CCl}_{2}^{2+} \stackrel{\mathrm{CAD}}{\longrightarrow} \mathrm{Cl}_{2}^{+}+\mathrm{C}^{+}$Renction}

This low intensity process has been recorded with a $70 \%$ primary beam transmittance of $\mathrm{He}$ or $\mathrm{Xe}(1.2$ collisions on average per affected species) to reach an acceptable signal-to-noise ratio (Figure $4 \mathrm{a}$ ). Let us note that the cross section for the production of $\mathrm{Cl}_{2}^{+}$is 22 times larger with He than with Xe.

This spectrum is much easier to analyze than the one associated with the $\mathrm{CCl}^{+}+\mathrm{Cl}^{+}$channel because only one isotopic contribution is present and because the neutral moiety lost is lighter, so that the fragment ion carries less kinetic energy in the laboratory frame. The kinetic energy release distribution can be extracted by numerical differentiation [47, 49], which leads to the data presented in Figure $4 \mathrm{~b}$. It emerges directly from these distributions that two processes characterized by quite different energy ranges take place. Dissociative SEC appears in the smaller kinetic energy range, whereas CAD manifests itself by the wider peak at higher kinetic energy. This second contribution starts to increase at a kinetic energy release value of $\varepsilon_{\min }=$ $3.5 \mathrm{eV}$ and reaches a maximum at $\varepsilon=5.8 \mathrm{eV}$.

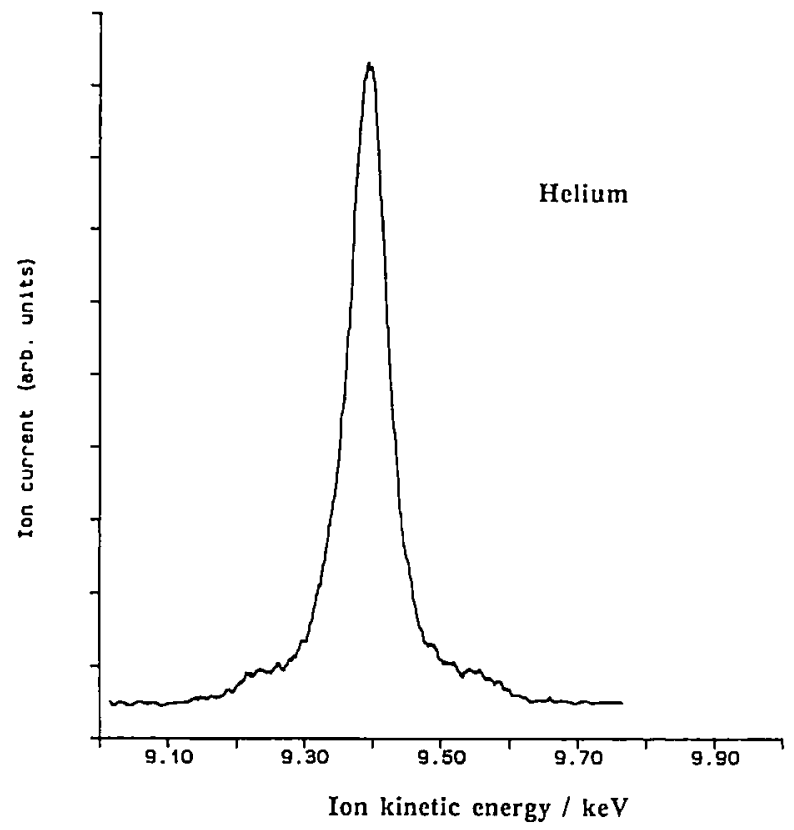

From this kinetic energy release distribution, we calculate a CAD/dissociative SEC ratio of 0.28 for He and 0.32 for $\mathrm{Xe}$. These values must be compared to the data reported in Table 2 for the production of $\mathrm{CCl}^{+}$: with $\mathrm{He}$ and $\mathrm{Xe}$ as target gases, the measured ratios were equal to 0.9 and 0.15 , respectively.

To calculate the branching ratio between the $\mathrm{CCl}^{+}+$ $\mathrm{Cl}^{+}$and the $\mathrm{Cl}_{2}^{+}+\mathrm{C}^{+}$channels from the daughter ion spectra (Figure 2 and Table 1), one additional fact has to be considered. The ion kinetic energy bandpass, which was given by $\Delta E_{\mathrm{k}} / E_{\mathrm{k}}=2.5 \times 10^{-3}$ in our linked scans at constant $B / E$, does not span the whole range of kinetic energy released in the laboratory frame. As an example, this range is equal to $1000 \mathrm{eV}$ for the $\mathrm{CCl}^{+}+\mathrm{Cl}^{+}$channel (Figure 3) at an ion kinetic energy of $14 \mathrm{keV}$. As a consequence, the fragment ion yield is artificially lowered in a daughter ion spectrum obtained by linked scanning. This effect becomes larger when the kinetic energy released on the observed fragment ion increases. Corrected intensities $I_{\text {frag }}^{\mathrm{cor}} \mathrm{CAD}$ can be obtained via the following formula [50] if both daughter ion spectra and ion kinetic energy spectra have been measured at compatible accelerating voltages:

$$
\begin{aligned}
& I_{\text {frag }}^{\text {cor }}
\end{aligned}
$$

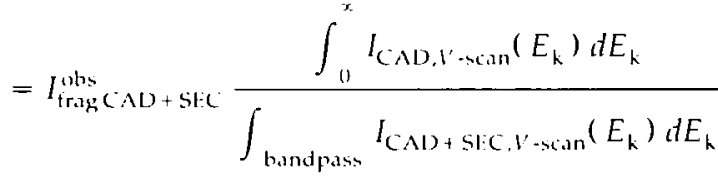

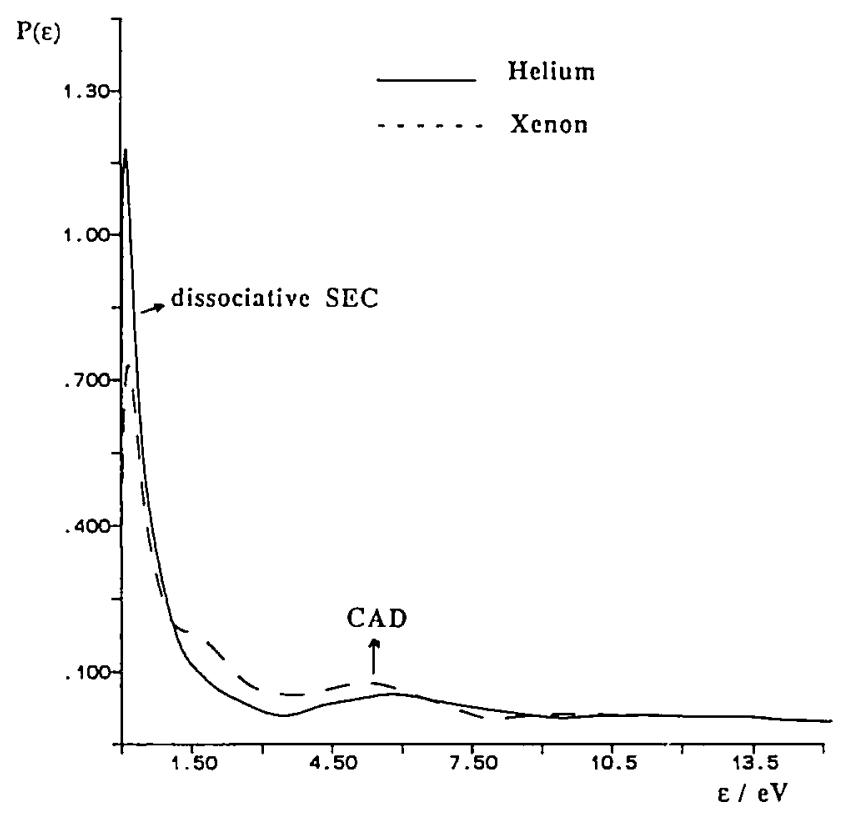

Figure 4. (a) $\mathrm{Cl}_{2}^{+}$ion kinetic energy spectrum obtained by the accelerating voltage scan technique. $\mathrm{Cl}_{2}^{+}$ions result from collision between $\mathrm{CCl}_{2}^{\frac{2}{+}}$ ions and He. Primary beam transmittance: $70 \%$. (b) Kinetic energy release distribution obtained by numerical differentiation of the corresponding ion kinetic energy spectrum. Solid line: target gas $=\mathrm{He}$; dashed line: target gas $=\mathrm{Xe}$. 
where $I_{\text {frag CAD }+S E C}^{\text {obs }}$ is the intensity measured in a linked scan spectrum at constant B/E, I IAD,V scan $\left(E_{k}\right)$ is the CAD contribution in the ion kinetic energy spectrum ( $V$-scan) of the fragment of interest, and $I_{\mathrm{CAD}+\operatorname{SIC}, V-\mathrm{scan}}\left(E_{\mathrm{k}}\right)$ is the total intensity $(\mathrm{CAD}+\mathrm{SEC})$ of the ion kinetic energy spectrum of the considered fragment.

By using eq 7 and the CAD/SEC separation procedure outlined in the preceding text with a coherent set of data measured at a $70 \%$ primary beam transmittance, we obtained the following corrected branching ratios between the $\mathrm{CCl}^{+}+\mathrm{Cl}^{+}$and the $\mathrm{Cl}_{2}^{+}+\mathrm{C}^{+}$channels: $I\left(\mathrm{Cl}_{2}^{+}+\mathrm{C}^{+}\right) / I\left(\mathrm{CCl}^{+}+\mathrm{Cl}^{+}\right)=0.10$ and 0.31 with, respectively, $\mathrm{He}$ and $\mathrm{Xe}$ as the target gas. With He at $30 \%$ primary beam transmittance, the same procedure led to a ratio equal to 0.02 .

\section{Semiempirical Calculations and Discussion}

To help interpret the experimental data, we calculated, at the MNDO level, cross sections, equilibrium geometries, and transition states for the first electronic states of the $\mathrm{CCl}_{2}^{2+}$ dication. These calculations were per- formed by using the AMPAC package [48]. Briefly, the underlying approximations are the following:

1. Only the valence electrons are considered.

2. We have included a limited configuration interaction (CI), which takes into account all excitations within the two highest occupied and the first three virtual molecular orbitals of the ground electronic state.

\section{Equilibrium Geometries and Heats of Formation of} $\mathrm{CCl}_{2}^{2+} \tilde{X}^{1} \Sigma_{\xi}^{+}$and $\mathrm{CCl}_{2}^{2+} \tilde{a} \Sigma_{u}^{-}$

The calculated equilibrium geometries and heats of formation are summarized in Table 3. The ground state is linear and corresponds to the following electronic configuration:

$$
\begin{aligned}
& \mathrm{CCl}_{2}^{2}+\tilde{X}^{1} \Sigma_{\mathrm{r}}^{+} \\
& \quad \cdots\left(5 \sigma_{\mathrm{h}}\right)^{2}\left(4 \sigma_{\mathrm{u}}\right)^{2}\left(6 \sigma_{\mathrm{g}}\right)^{2}\left(5 \sigma_{\mathrm{u}}\right)^{2}\left(2 \pi_{\mathrm{u}}\right)^{4}\left(2 \pi_{\mathrm{g}}\right)^{4}\left(3 \pi_{\mathrm{u}}\right)^{10}
\end{aligned}
$$

Table 3. Equilibrium geometries and heats of formation for different isomers and electronic states

\begin{tabular}{|c|c|c|}
\hline Electronic state & Equilibrium geometry & $\begin{array}{l}\text { Heat of formation } \\
\left(\mathrm{kJ} \mathrm{mol} \mathrm{mo}^{-1}\right)\end{array}$ \\
\hline $\mathrm{CCl}_{2}^{2} \cdot \bar{X}^{1} \Sigma_{9}$ & $\begin{array}{l}\text { Cl level } \\
C_{2 v} \text { point group } \\
\mathrm{R}(\mathrm{C}-\mathrm{Cl})=1.57 \AA \\
\mathrm{Cl}-\mathrm{C}-\mathrm{Cl} \text { angle }=180^{\circ}\end{array}$ & 2788 \\
\hline $\mathrm{CCl}_{2}^{2} \cdot \bar{X}^{1} A^{\prime}$ & $\begin{array}{l}\text { SCF level } \\
C_{S} \text { point group } \\
\mathrm{R}\left(\mathrm{Cl}_{1}-\mathrm{Cl}_{2}\right)=2.1 \AA \\
\mathrm{R}\left(\mathrm{Cl}_{2}-\mathrm{C}\right)=1.9 \AA \\
\mathrm{Cl}-\mathrm{Cl}-\mathrm{C} \text { angle }=114^{\circ}\end{array}$ & 3129 \\
\hline & $\begin{array}{l}C \text { level } \\
C_{S} \text { point group } \\
R\left(C_{1}-C_{2}\right)=2.00 \AA \\
R\left(C l_{2}-C\right)=1.94 \AA \\
C l-C l-C \text { angle }=111^{\circ}\end{array}$ & 3168 \\
\hline $\mathrm{CCl}_{2}^{2} \bar{X}^{1} A^{\prime}$ (saddle point) & $\begin{array}{l}\text { SCF level } \\
C_{S} \text { point group } \\
\mathrm{R}\left(\mathrm{Cl}_{1}-\mathrm{C}\right)=1.72 \AA \\
\mathrm{R}\left(\mathrm{Cl}_{2}-\mathrm{C}\right)=1.83 \AA \\
\mathrm{Cl}-\mathrm{C}-\mathrm{Cl} \text { angle }=86.5^{\circ}\end{array}$ & 3339 \\
\hline $\mathrm{CCl}_{2}^{2} \cdot \bar{a}^{3} \mathrm{Y}_{\mathrm{u}}$ & $\begin{array}{l}\mathrm{Cl} \text { level } \\
C_{2 v} \text { point group } \\
\mathrm{R}(\mathrm{C}-\mathrm{Cl})=1.61 \AA \\
\mathrm{Cl}-\mathrm{C}-\mathrm{Cl} \text { angle }=180^{\circ}\end{array}$ & 3089 \\
\hline
\end{tabular}
of $\mathrm{CCl}_{2}^{2}+$ 
The first triplet excited state is also linear and is described by the following major configuration:

$$
\begin{aligned}
\mathrm{CCl}_{2}^{2}+\bar{a}^{3} \Sigma_{\mathrm{u}}^{-} & \\
& \cdots\left(5 \sigma_{\mathrm{g}}\right)^{2}\left(4 \sigma_{\mathrm{u}}\right)^{2}\left(6 \sigma_{\mathrm{g}}\right)^{2}\left(5 \sigma_{\mathrm{u}}\right)^{2}\left(2 \pi_{\mathrm{u}}\right)^{4}\left(2 \pi_{\mathrm{g}}\right)^{3}\left(3 \pi_{\mathrm{u}}\right)^{1}
\end{aligned}
$$

Let us notice that the isoelectronic CS2 molecule behaves very similarly [51]. Its first triplet state is bent (valence angle of $135.8^{\circ}$ ) and belongs to the $A_{2}$ representation in the $C_{21}$, point group: this representation correlates to the $\Sigma_{u}^{-}$representation of the $D_{x / l}$ group. The valence angle is larger in $\mathrm{CCl}_{2}^{2+}$ owing to the repulsion beween the two charges. Furthermore the excitation energy of this triplet state is about the same for both species (301 kJ mol-1 for $\mathrm{CCl}_{2}^{2+}$ and $313.2 \mathrm{~kJ}$ $\mathrm{mol}^{-1}$ for $\mathrm{CS}_{2}$ ) [51].

\section{$\mathrm{CCl}_{2}^{2+} \stackrel{\mathrm{CAD}}{\longrightarrow} \mathrm{CCl}^{+}+\mathrm{Cl}^{+}$Dissociation Channels}

The two following processes are symmetry and spin allowed:

$$
\begin{aligned}
& \mathrm{CCl}_{2}^{2+}\left(\bar{X}^{1} \Sigma_{\mathrm{g}}^{+}\right) \rightarrow \mathrm{CCl}^{+}\left(X^{1} \Sigma^{+}\right)+\mathrm{Cl}^{+}\left({ }^{1} D_{\mathrm{g}}\right) \\
& \mathrm{CCl}_{2}^{2+}\left(\tilde{\pi}^{3} \Sigma_{\mathrm{u}}^{-}\right) \rightarrow \mathrm{CCl}^{+}\left(X^{1} \Sigma^{+}\right)+\mathrm{Cl}^{+}\left({ }^{3} P_{\mathrm{g}}\right)
\end{aligned}
$$

We have calculated a cross section in the potential energy surfaces of $\mathrm{CCl}_{2}^{2+}$ along the $\mathrm{R}(\mathrm{C}-\mathrm{Cl})$ coordinate under the following conditions: (1) linear geometry; (2) one $\mathrm{C}-\mathrm{Cl}$ distance was frozen at $1.66 \AA$, that is, the equilibrium internuclear distance of $\mathrm{CCl}^{+}\left(X^{1} \Sigma^{+}\right)$.

The results presented in Figure 5 show that the above-mentioned symmetry correlation is well accounted for. The dissociation barrier associated with the ground state of the dication, which leads to excited $\mathrm{Cl}^{+}$, is equal to $630 \mathrm{~kJ} \mathrm{~mol}^{-1}$, whereas the corresponding barrier to produce ground state fragments from the first triplet state of $\mathrm{CCl}_{2}^{2+}$ is equal to $142 \mathrm{~kJ} \mathrm{~mol}^{-1}$. The singlet and triplet states cross at a C-Cl distance of 2.15 $\AA$, where a spin-orbit interaction takes place. This

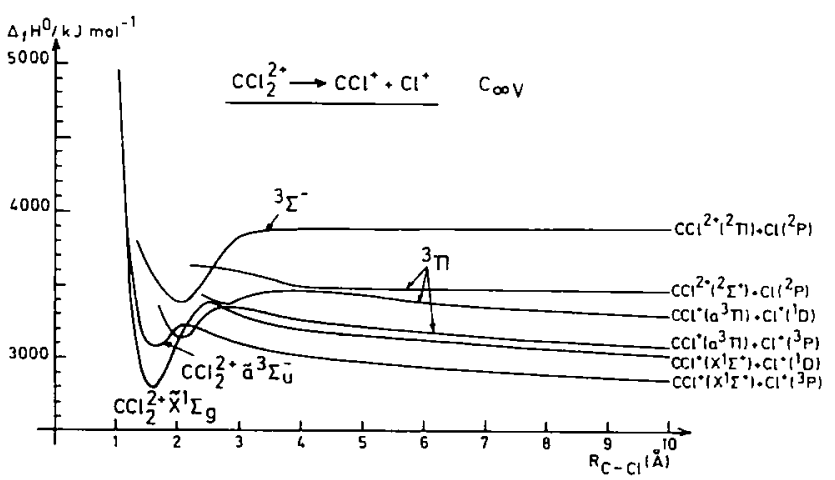

Figure 5. Cross section in the potential energy surfaces of different $\mathrm{CCl}_{2}^{2+}$ electronic states along one $\mathrm{C}-\mathrm{Cl}$ coordinate. Linear geometry. The second $\mathrm{C}-\mathrm{Cl}$ distance is frozen at $1.66 \AA$. These calculations were performed at the MNDO level with limited configuration interaction (see text). spin-orbit coupling allows us to reach the ground state fragments from the ground state of the $\mathrm{CCl}_{2}^{2+}$ dication: the barrier that has to be crossed amounts to $420 \mathrm{~kJ} \mathrm{~mol}^{-1}$. We have not been able to detect a metastable signal for this fragmentation, so its rate constant must be higher than $10^{6} \mathrm{~s}^{-1}$. This is not surprising for an ion that contains heavy atoms like $\mathrm{Cl}$, which induce substantial spin-orbit interactions. The calculated reverse activation barrier associated with the ground state fragments is then equal to $5.2 \mathrm{eV}$, whereas the reverse barrier that corresponds to $\mathrm{CCl}^{+}\left(X^{1} \Sigma^{+}\right)+\mathrm{Cl}^{+}\left({ }^{1} D\right)$ is equal to $4.8 \mathrm{eV}$. In view of the uncertainties associated with semiempirical calculations, both values are qualitatively compatible with the experimental kinetic energy releases. Their difference is too small to distinguish experimentally between both processes.

At large internuclear distances, the $\mathrm{Cl}^{+}-\mathrm{CCl}^{+}$ ion-ion Coulombic repulsion becomes dominant. The cross section in the potential energy surface is then given by the Coulomb equation, which is expected to be valid until the interfragment interactions become significant. The comparison between the MNDO results and the Coulomb equation as well as the examination of the atomic charge analysis show that orbital overlap appears at distances smaller than $6 \AA$. Because the spin-orbit coupling zone is located around $2.1 \AA$, the role of exit channel interactions must be considered. We have compared the cross sections calculated for a frozen $\mathrm{CCl}^{+}$geometry (Figure 5) with data obtained by allowing $\mathrm{CCl}^{+}$geometry relaxation, to minimize the energy. The largest discrepancy observed between both sets of data amounts to $15 \mathrm{~kJ} \mathrm{~mol}^{-1}$. This suggests that no significant exit channel interaction takes place and that the smallest kinetic energy release observed and the reverse activation barrier may be compared.

\section{$\mathrm{CCl}_{2}^{2+} \stackrel{\mathrm{CAD}}{\longrightarrow} \mathrm{Cl}_{2}^{+}+\mathrm{C}^{+}$Dissociation Channel}

The $\mathrm{CCl}_{2}^{2+}\left(\bar{X}^{1} \Sigma_{h}^{+}\right) \rightarrow \mathrm{Cl}_{2}^{+}\left(X^{2} \mathrm{II}_{\mathrm{g}}\right)+\mathrm{C}^{+}\left({ }^{2} P_{\mathrm{u}}\right)$ reaction is allowed by both symmetry and spin conservation. This reaction requires a rearrangement from the $\mathrm{Cl}-\mathrm{C}-\mathrm{Cl}$ structure to a $\mathrm{Cl}-\mathrm{Cl}-\mathrm{C}$ structure more likely to lose a $\mathrm{Cl}_{2}^{+}$fragment. MNDO calculations find a shallow minimum that corresponds to such a structure on the ground state potential energy surface of $\mathrm{CCl}_{2}^{2}$. This structure is described in Table 3, as well as that of the transition state for the isomerization process. The isomerization barrier is then equal to $550 \mathrm{~kJ} \mathrm{~mol}^{-1}$ and is therefore much larger than the dissociation barrier to $\mathrm{CCl}^{+}+\mathrm{Cl}^{+}\left({ }^{3} \mathrm{P}\right)$.

The dissociation barrier from the $\mathrm{ClClC}^{2+}$ structure to the $\mathrm{Cl}_{2}^{+}+\mathrm{C}^{+}$fragments, calculated at the $\mathrm{CI}$ level, is very low $\left(5 \mathrm{~kJ} \mathrm{~mol}^{-1}\right)$. At this level of calculation, such a value is too low to decide whether the $\mathrm{Cl}-\mathrm{Cl}_{-} \mathrm{C}^{2+}$ structure is stable or not. These calculations reveal, however, that the barrier originates from an avoided crossing between states that have $\left(15 a^{\prime}\right)^{2}$ and 
$\left(15 a^{\prime}\right)^{1}\left(16 a^{\prime}\right)^{\prime}$ as leading configurations and that the mixing between both states is still present at the $\mathrm{Cl}-\mathrm{Cl}$ $\mathrm{C}^{2+}$ equilibrium geometry. This suggests that only a high-level ab initio calculation with variational $\mathrm{CI}$ possibly could be able to describe properly this structure and its dissociation barrier, if any. Nevertheless, we can already conclude that the observed kinetic energy release on the $\mathrm{Cl}_{2}^{+}+\mathrm{C}^{+}$fragments is governed by the isomerization barrier, which will be much higher than the dissociation barrier. The known experimental and theoretical data on the reactivity of $\mathrm{CCl}_{2}^{2+}$, both from the literature and from the present work, are summarized in Figure 6. We calculate a reverse activation barrier that corresponds to the $\mathrm{Cl}_{2}^{+}+\mathrm{C}^{+}$asymptote equal to $4.4 \mathrm{eV}$, which is compatible with the $\varepsilon_{\min }=3.5$ $\mathrm{eV}$ measured for this dissociation.

Let us note that the three reverse activation barriers calculated by the MNDO method are in the same range $(4.4-5.2 \mathrm{eV})$; so are the experimental kinetic energy releases $\varepsilon_{\min }(3.5-3.9-\mathrm{eV}$ range). This suggests that the relative heights of the dissociation barriers are well reproduced by the semiempirical calculations.

\section{Competition between the $\mathrm{CCl}^{+}+\mathrm{Cl}^{+}$and $\mathrm{Cl}_{2}^{+}+$} $\mathrm{C}^{+}$Channels

The data presented in the section related to the experimental results show that the branching ratio between these two channels varies with the collision gas used and thus with the amount of internal energy deposited in the $\mathrm{CCl}_{2}^{2+}$ ion. The harder target gas, $\mathrm{He}$, leads to a smaller $\mathrm{I}\left(\mathrm{Cl}_{2}^{+}+\mathrm{C}^{+}\right) / I\left(\mathrm{CCl}^{+}+\mathrm{Cl}^{+}\right)$branching ratio. A further increase in the internal energy by increasing the target gas pressure, and thus the number of collisions, also leads to a decrease of the branching ratio.

We suggest the following explanation to rationalize these data. Three channels are in fact in competition. In order of increasing appearance energy, they are:

$$
\begin{aligned}
& \mathrm{CCl}_{2}^{2+} \rightarrow \mathrm{CCl}^{+}\left(X^{1} \Sigma^{+}\right)+\mathrm{Cl}^{+}\left({ }^{3} P\right) \quad \text { (channel 1) } \\
& \mathrm{CCl}_{2}^{2+} \rightarrow \mathrm{Cl}_{2}^{+}\left(X^{2} \Pi_{\mathrm{g}}\right)+\mathrm{C}^{+}\left({ }^{2} P\right) \quad \text { (channel 2) } \\
& \mathrm{CCl}_{2}^{2+} \rightarrow \mathrm{CCl}^{+}\left(X^{1} \Sigma^{+}\right)+\mathrm{Cl}^{+}\left({ }^{1} D\right) \quad \text { (channel 3) }
\end{aligned}
$$

In the internal energy regime where only channels 1 and 2 are opened, their competition is controlled by their respective barrier heights and by the spin-orbit transition probability. Because the experimental data show that channel 1 is favored, the barrier height effect must be dominant. When channel 3 becomes open, the behavior as a function of the internal energy must change. The rate constant is expected to increase more rapidly with internal energy for process 3 than for processes 1 and 2 because the latter processes have important bottlenecks:

1. The spin-orbit transition probability, which can be approximated by the Landau-Zener formula [52], decreases with increasing internal energy.

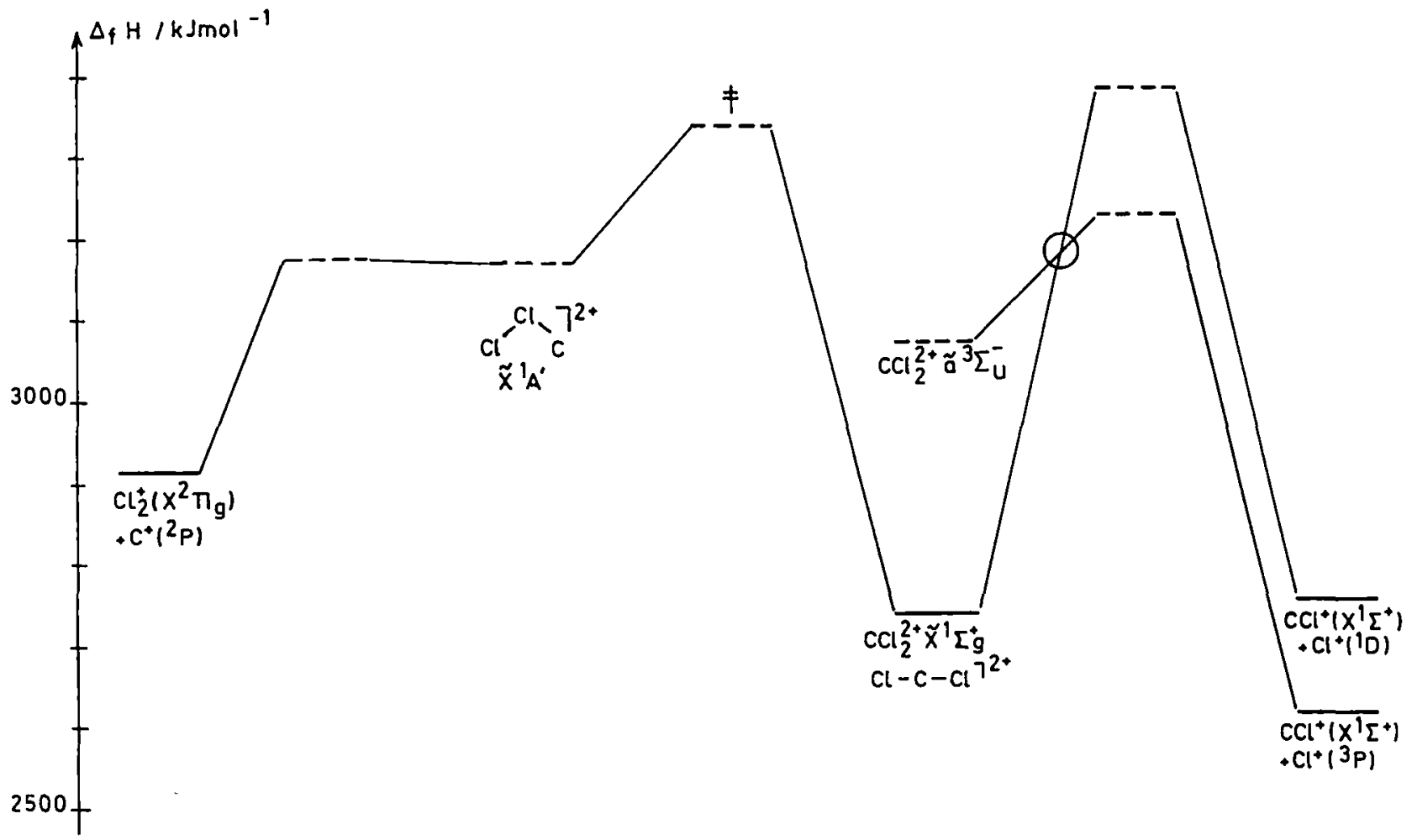

Figure 6. Schematic energy profile for the $\mathrm{CCl}_{2}^{2+}$ dissociation pathways discussed in this article. Solid lines: experimental data; dashed lines: calculated data (this work). 
2. Channel 2 requires an isomerization step and is entropically disfavored.

As a result, channel 3 is expected to become dominant at higher internal energy, which results in a more intense $\mathrm{CCl}^{+}$ion current. The kinetic energy release expected for reactions 1 and 3 is unfortunately not different enough to allow us to distinguish experimentally between them. Of course, the internal energy distribution produced upon CAD is quite broad and embraces both energy regimes under discussion, so that the observed effect is an overall decrease of the $\mathrm{Cl}_{2}^{+}$abundance, when one switches from a softer to a harder target.

\section{Conclusion}

Collision between fast (kiloelectronvolt energy range) doubly charged ions and a neutral target leads among other processes to collisionally activated dissociation and to single-electron capture. We have investigated these processes in the case of the dichlorocarbene dication, with emphasis in this article on the reactivity of the collisionally activated dication. Daughter ion spectra, ion kinetic energy spectra, and semiempirical theoretical calculations were the main tools of investigation used. CAD is favored compared to SEC when high ionization energy targets are used. Analysis of the ion kinetic energy spectra allows us to distinguish between the CAD and dissociative SEC contributions.

The major reaction channels are $\mathrm{CCl}_{2}^{2} \cdot \stackrel{\mathrm{CAD}}{\longrightarrow}$ $\mathrm{CCl}^{-}\left(X^{1} \Sigma^{+}\right)+\mathrm{Cl}^{+}\left({ }^{3} P\right.$ and $\left.{ }^{\prime} D\right)$ and $\mathrm{CCl}_{2}^{-} \stackrel{\mathrm{CAD}}{\longrightarrow}$ $\mathrm{Cl}_{2}^{+}+\mathrm{C}^{+}$. The former channels dominate. Production of ground state $\mathrm{CCl}^{+}\left(X^{\prime} \Sigma^{+}\right)+\mathrm{Cl}^{+}\left({ }^{3} P\right)$ fragments involves a spin-orbit coupling induced transition between the ground electronic state of $\mathrm{CCl}_{2}^{2}$ and its first triplet excited state. The calculated barrier to dissociation amounts to $420 \mathrm{~kJ} \mathrm{~mol}^{-1}$, whereas the reverse activation barrier is compatible with the observed kinetic energy released on the fragments.

The $\mathrm{CCl}_{2}^{2+} \stackrel{\mathrm{CAD}}{\longrightarrow} \mathrm{Cl}_{2}^{+}+\mathrm{C}^{-}$channel is characterized by a two-step mechanism. An isomerization process with a barrier equal to $550 \mathrm{~kJ} \mathrm{~mol}^{-1}$ leads to a $\mathrm{Cl}-\mathrm{Cl}-\mathrm{C}^{2+}$ structure from which dissociation occurs. The lower branching ratio for this channel is in keeping with the high isomerization barrier compared to the dissociation barrier to $\mathrm{CCl}^{+}\left(X^{1} \Sigma^{+}\right)+\mathrm{Cl}^{+}\left({ }^{3} P\right)(420$ $\left.\mathrm{kJ} \mathrm{mol}{ }^{-1}\right)$. The reverse activation barrier is here also in agreement with the measured kinetic energy release.

When the internal energy deposited in the $\mathrm{CCl}_{2}^{2}$. ion is increased, production of $\mathrm{CCl}^{+}\left(X^{1} \Sigma^{+}\right)+\mathrm{Cl}^{+}\left({ }^{2} D\right)$ becomes more favorable, which leads to a decrease of the $\mathrm{Cl}_{2}^{+}$relative abundance.

The spectroscopic properties of $\mathrm{CCl}_{2}^{2+}$ calculated in this article (geometries and excitation energy) show strong similarities with the known data on the isoelectronic CS2 molecule [51]. This is in agreement with the "chemical bond plus electrostatic repulsion model" for molecular dications [13].
The dissociative single-electron-capture process has been mentioned only briefly in this article. It will be discussed in detail in a forthcoming paper. The major dissociation channel there also is $\mathrm{CCl}^{+}+\mathrm{Cl}$. The dissociation dynamics is governed by the mechanism for the charge exchange reaction, which depends strongly on its endothermicity or exothermicity.

\section{Acknowledgments}

B.L. wishes to express his gratitude to Professor Fred McLafferty, who introduced him with such a contagious enthusiasm to the exciting field of mass spectrometry. We are grateful to Professor Robert Locht for a critical reading of the manuscript. Support through grants from the Belgian Fonds de la Recherche Fondamentale Collective (2.4537.91F and 2.4532.95), from the Loterie Nationale (9.4610.90), and from the University of Liège is gratefully acknowledged.

\section{References}

1. Mclafferty, F. W.; Bente, P. F., IIl; Kornfeld, R.; Tsai, S.-C.; Howe, I. I. Am. Che'm. Soc. 1973, 95, 2120-2129.

2. McLafferty, F. W., Ed. Tandem Mass Spectromitry; Wiley-Interscience: New York, 1983.

3. Busch, K. L.; Glish, G. L.; McLuckey, S. A. Mass Spectrometry/Mass Spectrometry; VCH: Weinheim, 1988.

4. Mcluckey, S. A. I. Ant. Soc. Mass Spectrom. 1992, 3, 599-614.

5. Cooks, R. G.; Beynon, 1. H.; Ast, T. /. Am. Ch'm. Sot. 1972, 94, 1004-1006.

6. Vékey, K.; Brenton, A. C.; Beynon, J. H. I. M/ys. Ch'm. 1986, $90,3569-3577$.

7. Mathur, B. P.; Abbey, L. E.; Burgess, E. M.; Moran, T. F. Org. Mass Spetrom. 1980, 15, 312-316.

8. Appling, J. R.; Burdick, G. W.; Moran, T. F. Org. Mass Spectrom. 1985, 20, 343-350.

9. Harris, F. M. lint. I. Mass Spectroml. lon Processe's 1992, 120, $1-4.3$.

10. Harris, F. M. In Plusics of lon Impacl Phenome'na; Mathur, D., Ed.; Springer: Berlin, 1991; pp 199-223.

11. Marathe, V. R.; Mathur, D. In Physics of Ion Imphat Phe'nomena; Mathur, D., Ed.; Springer: Berlin, 1991; pp 225-274.

12. Jonathan, P.; Hamdam, M.; Brenton, A. G.; Willett, G. D. Chom. Phys. 1988, 179, 159-170.

13. Senekowitsch, J: O'Neil, S.; Meyer, W. Thorr. Chim. Acto 1992, $84,85-93$.

14. Aitken, R. A. Org. React. Mich. 1988, 1986, 227-246; 1989, 1987, 247-269.

15. Andrews, L.; Keelan, B. W. I. Am. Chom. Soc. 1979, 101, $3500-3504$.

16. Nguyen, M. T.; Kerins, M. C.; Hegarty, A. F.; Fitzpatrick, N. J. Chem. Phys. Letl. 1985, 117, 295-300.

17. Rademann, K.; Jochims, H.-W.; Baumgärtel, H. I. Phys. Chomt. 1985, 89, 3459-3464

18. Paulino, J. A.; Squires, R. R. 1. Am. Ch'm. Soc. 1991, 11.3, 5573-5580.

19. Leyh, B.; Wankenne, H. Int. I. Mass Spectrom. Lum Processes $1991,107,453-474$.

20. Werner, A. S.; Tsai, B. P.; Baer, T. I. Ch'm. Phys. 1974, 60, $3650-3657$

21. Drewello, T.; Weiske, T.; Schwarz, H. Angen'. Ch'm. IIIt. Edt. Eligl. 1985, 24, 869-870.

22. Bews, J. R.; Glidewell, C. I. Mol. Strict. 1981, 71, 287-296. 
23. Hop, C. E. C. A.; Holmes, J. L.; Lossing, F. P.; Terlouw, J. K. 1ht. I. Mass Spectrom. Ion Processe's 1988, 83, 285-294.

24. Leiter, K.; Stephan, K.; Märk, E.; Märk, T. D. Plasma Chem. Plasma Proc. 1984, 4, 235-249.

25. Leiter, K.; Scheier, P.; Walder, G.; Märk, T. D. Int. /. Mass Spectrom. Ion Processes 1989, 87, 209-224.

26. Creasey, J. C.; Lambert, I. R.; Tuckett, R. P.; Codling, K.; Frasinski, L. J.; Hatherly, P. A.; Stankiewicz, M.; Holland, D. M. P. I. Che'm. Phys. 1990, 93, 3295-3306.

27. Burton, G. R.; Chan, W. F.; Cooper, G.; Brion, C. E. Chem. Phys. 1994, 181, 147-172.

28. Proctor, C. J.; Porter, C. J.; Ast, T.; Beynon, J. H. Int. I. Mass Spectrom. Ion Phys. 1982, +1, 251-263.

29. Langford, M. L.; Hamdam, M.; Harris, F. M. Int. I. Mass Spectrom. lon Processes 1990, 95, 243-258.

30. Guenat, C.; Maquin, F.; Stahl, D.; Koch, W.; Schwarz, H. Int 1. Mars Spectrom. Ion Processe's 1985, 63, 265-272.

31. Drewello, T.; Koch, W.; Weiske, T.; Schwarz, H.; Stahl, D. Int. 1. Mass Spetrom. lon Processes 1986, 72, 313-315.

32. Beynon, J. H.; Cooks, R. G.; Jennings, K. R.; Ferrer-Correia, A. J. Int. I. Mass Spectrom. lon Phys. 1975, 18, 87-99.

33. Wankenne, H.; Momigny, J. lit. I. Mass Spectromn. Lon Phys. $1971,7,227-243$.

34. Boyd, R. K.; Beynon, J. H. Org. Mass Spedrom. 1977, 12, 163-165.

35. Barber, M.; Elliott, R. M. 12th Annual Conference on Mass Spectrontery and Allied Topics, Montreal, 1964; ASTM Committee E14.

36. Todd, P. J.; McLafferty, F. W. Iht. I. Mass Spectrom. Ion Phys. 1981, 38, 371-378.

37. Holmes, J. L. Org. Mass Spectrom. 1985, 20, 169-183.

38. Rosenstock, H. M.; Draxl, K.; Steiner, B. W.; Herron, J. T. I. Phys. Chem. Re\%. Dath 1977, 6, Suppl. 1.
39. Lias, S. G.; Bartmess, J. E.; Liebman, J. F.; Holmes, J. L.; Levin, R. D.; Mallard, W. G. J. Phys. Chem. Ref. Data 1988, 17, Suppl. 1.

40. Kim, M. S.; McLafferty, F. W. I. Am. Chem. Soc. 1978, 100, 3279-3282.

41. Cooks, R. G.; Beynon, J. H.; Caprioli, R. M.; Lester, G. R. Metastable lons; Elsevier Scientific: Amsterdam, 1973; p 62.

42. Klots, C. E. Z. Naturforsch. 1972, 27a, 553-561.

43. Klots, C. E. I. Chem. Phys. 1973, 58, 5364-5367.

44. Klots, C. E. J. Chem. Phys. 1976, 64, 4269-4275.

45. Baer, T.; Willett, G. D.; Smith, D.; Phillips, J. S. J. Chem. Phys. 1979, 70, 4076-4085.

46. Mukhtar, E. S.; Griffiths, I. W.; March, R. E.; Harris, F. M.; Beynon, J. H. Int. I. Mass Spectrom. Ion Phys. 1981, 41, 61-82.

47. Holmes, J. L.; Osborne, A. D. Int. I. Mass Spectrom. Ion Phys. 1977, 23, 189-200.

48. Dewar Research Group, The AMPAC package (containing the MINDO/3, MNDO, and AM1 methods) Chemistry Department, University of Texas, Austin, TX 78712. The package was converted for an 1BM3090 computer by R. Farren and E.R. Davidson, Department of Chemistry, Indiana University, Bloomington, IN 47405, and is distributed by the Quantum Chemistry Program Exchange under reference number 539.

49. Terwilliger, D. T.; Elder, J. F., Jr.; Beynon, J. H.; Cooks, R. G Int. I. Mass Spectrom. Ion Plnys. 1975, 16, 225-242.

50. Leyh, B.; Hoxha, A. Chem. Phys. 1995, 192, 65-77.

51. Herzberg, G. Molecular Spectra and Molecular Stricture. III. Electronic Spectra and Electronic Structure of Polyatomic Molecules; Van Nostrand: London, 1967; p 601.

52. Landau, L. Phys. Z. Sorujutumion 1932, 1, 88-98; Zener, C. Proc. R. Soc. London, 1932, A137, 696-702. 